\title{
Sistema de Visão por Infravermelho Próximo para Monitoramento de Processos de Soldagem a Arco
}

\author{
(Near-Infrared Vision System for Arc-Welding Monitoring)
}

\author{
Carolina Pimenta Mota ${ }^{1}$, Marcus Vinícius Ribeiro Machado ${ }^{1}$, Roberto Mendes Finzi Neto ${ }^{1}$, Louriel Oliveira Vilarinho ${ }^{1}$ \\ ${ }^{1}$ Universidade Federal de Uberlândia-Faculdade de Engenharia Mecânica, Uberlândia, Minas Gerais, Brasil, cpimentamota@ \\ gmail.com,mvmachado@mecanica.ufu.br,robertofinzi@hotmail.com,vilarinho@mecanica.ufu.br
}

\begin{abstract}
Resumo
A visão, o sentido predileto do ser humano, e sua grande capacidade de captar, processar e interpretar grandes quantidades de dados de natureza visual tem sido, ao longo dos anos, um grande estímulo para o desenvolvimento de técnicas e de dispositivos tecnológicos que a reproduzam num sistema computacional. Nos processos de soldagem, a visão pode fornecer dados na inspeção e qualidade da junta soldada, no monitoramento de parâmetros, na correção de trajetórias até, por fim, no estudo dos fenômenos envolvidos no processo. Porém, a radiação luminosa emitida pelo arco representa uma barreira para tais estudos baseados na visualização do processo. Uma das formas utilizadas atualmente para se obter a visualização do processo, sem a interferência do arco, consiste em iluminar o processo com o infravermelho próximo e utilizar filtros de interferência (passa-faixa), em torno deste mesmo comprimento de onda, durante a aquisição das imagens. Uma solução para a iluminação infravermelha, de aplicação crescente, envolve o uso de diodos laser de alta potência, com baixo custo e menor complexidade de instalação do que os lasers convencionais. Desta forma, a proposta deste trabalho foi a criação de um sistema de visão dos processos de soldagem a arco, de baixo custo e alta flexibilidade, indo desde a caracterização dos espectros de emissão luminosa do arco, passando pela criação de uma topologia de acionamento para o diodo de alta potência no infravermelho próximo, respeitando suas limitações de uso e maximizando a potência luminosa emitida, criação dos circuitos de controle, escolha dos equipamentos e componentes ópticos e, por fim, projeto e aplicação de um protótipo em processos de soldagem. As limitações do sistema de visão, como um todo, foram encontradas através de sua aplicação com soldagem TIG e MIG/MAG. Nestes ensaios, embora não tenha sido capaz de sobrepor a luz do arco, o sistema desenvolvido proporcionou uma iluminação homogênea e em sincronia com a câmera, sendo que a principal limitação foi o grande tempo de exposição da câmera disponível. Sugere-se, ao final, utilizar o sistema na forma de um seguidor de juntas.
\end{abstract}

Palavras-chave: sistema de imagem; diodo laser; NIR; aquisição de dados; solda.

\begin{abstract}
Vision, the human being's favorite sense, and its great capacity to obtain, to process and to interpret great amount of visual nature data has been throughout the years a great inspiration for development of techniques and technological devices that reproduce it into a computational system. In welding processes, vision can supply information in inspection and welded joint's quality, in the parameters' monitoring, in trajectory correction and even, finally, in the study of the phenomena involved in the process. However, the luminosity/radiation emitted from the weld arc represents a barrier for these studies based in the process visualization. One of the forms currently used to visualize the process, without the interference of the arc's light, consists of illuminating the process with the near infrared light and, using band pass (interference) filters, around this exactly wave length, during the acquisition of the images. A solution for the near infrared illumination, of increasing application, involves the use of laser diodes of high power, with low cost and less complex installation than conventional lasers. Therefore, the proposal of this work is the project, construction and assessment of a vision system for welding processes with low cost and high flexibility. It is based on characterization of the spectrum of the weld arc, definition of a drive topology for the laser diode within its limitations of use and maximizing the emitted luminous power, built of control circuits, selection of optics equipment and components and, finally, project and application of a prototype for visualization of different arc-welding processes. The final assessment of the whole vision system was carried out during TIG and MIG/MAG welding. Although, during the welding, the system was not capable of overcoming the arc radiation, it provides a homogenous illumination in synchronism with the camera, whereby the main limitation was large shutter time. Eventually, it is suggested to employ the developed vision system for helping joint tracking.
\end{abstract}

Key-words: Image System; laser diode; NIR; data acquisition; welding.

(Recebido em 23/03/2012; Texto final em 01/11/2012).

Artigo originalmente publicado no CONSOLDA 2011 


\section{Introdução}

A soldagem é um dos principais processos de fabricação utilizados na indústria para a união de materiais, principalmente os metais, sendo cada vez mais necessário e mais empregado. Tendo isso em vista, a necessidade da garantia de qualidade e produtividade dos processos envolvidos nesta tarefa está em constante crescimento. Sendo um processo especial, com parâmetros interdependentes, muitos trabalhos de pesquisa são desenvolvidos com o intuito de alcançar um melhor entendimento de seus fenômenos envolvidos.

Uma das formas amplamente aplicadas, atualmente, para o auxílio dos estudos do processo de soldagem são os sistemas de visão. O uso de câmeras, de baixa ou alta velocidade, pode fornecer diversas informações úteis aos pesquisadores, que não são possíveis de se obter com a monitoração dos sinais elétricos usuais, como a corrente ou a tensão. Diferentes sistemas de visão podem fornecer informações específicas sobre o processo em andamento: a técnica de perfilografia ou back-lighting projeção da sombra de elementos na região da solda em uma superfície plana - visualiza as gotas em transferência como uma forma de estudo da transferência metálica [1], enquanto novos sistemas de visão têm como o objetivo a visualização direta do metal fundido e da junta propriamente dita, com uma gama de aplicações indo de estudo dos fenômenos na poça até seguidores de junta ou controladores online de parâmetros do processo.

A visualização da poça fundida pode dar informações sobre muitos aspectos da solda. Diversos estudos comprovam que a observação e o controle da poça fundida, e suas principais características, resulta na penetração e propriedades mecânicas desejadas [2-5]. Além disso, a aplicação de um sistema de auxílio visual vai muito além do controle da penetração em um processo de soldagem. Uma visualização nítida da superfície da poça fundida e sua deformação retêm informações importantes de vários fenômenos básicos, como o fluxo de Marangoni dentro da poça de soldagem [6].

$\mathrm{O}$ arco voltaico nos processos de soldagem emite, além da radiação luminosa visível, em praticamente todos os comprimentos de onda, incluindo radiações ultravioleta e infravermelha. A intensidade luminosa emitida, entretanto, em comprimentos de onda infravermelhos superiores a $850 \mathrm{~nm}$ é pequena quando comparada ao espectro visível. [5, 7]. Uma das técnicas de visualização do processo é a utilização de filtros passa longa nesta região de emissão, com o intuito de diminuir a

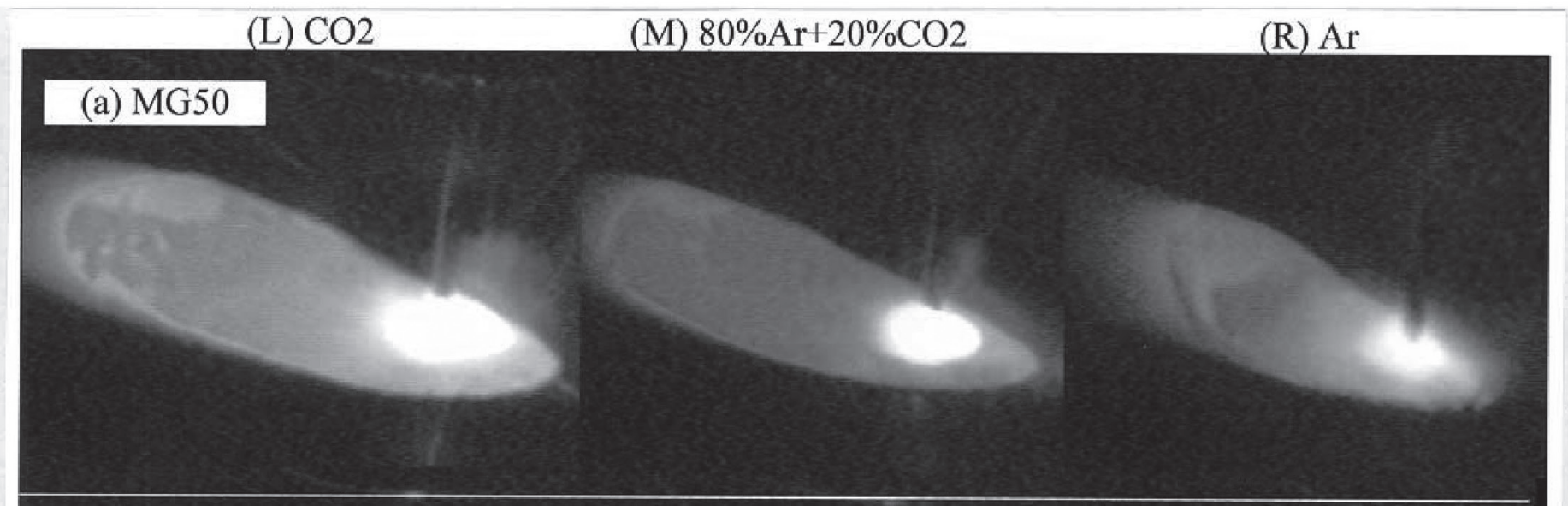

Figura 1. Imagens obtidas com filtro em $950 \mathrm{~nm}$ no estudo do processo MIG/MAG [8].

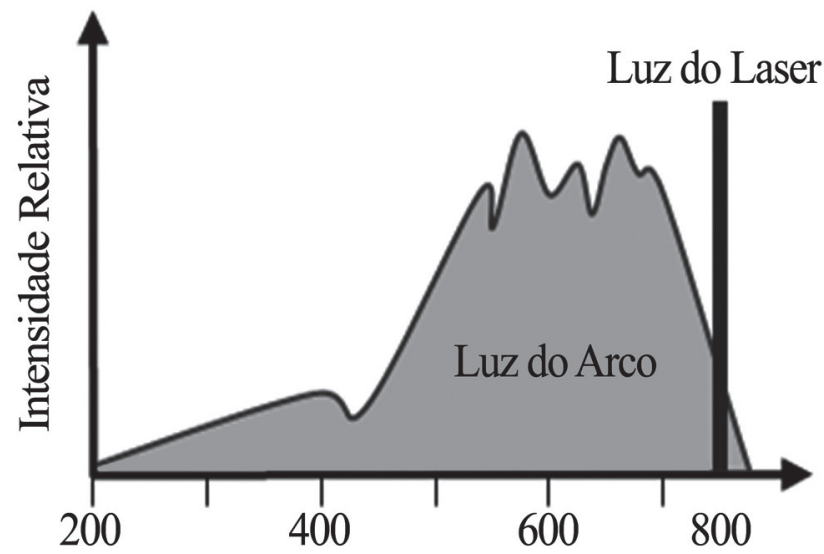

Comprimento de Onda, $\mathrm{nm}$

Sem filtro de interferência

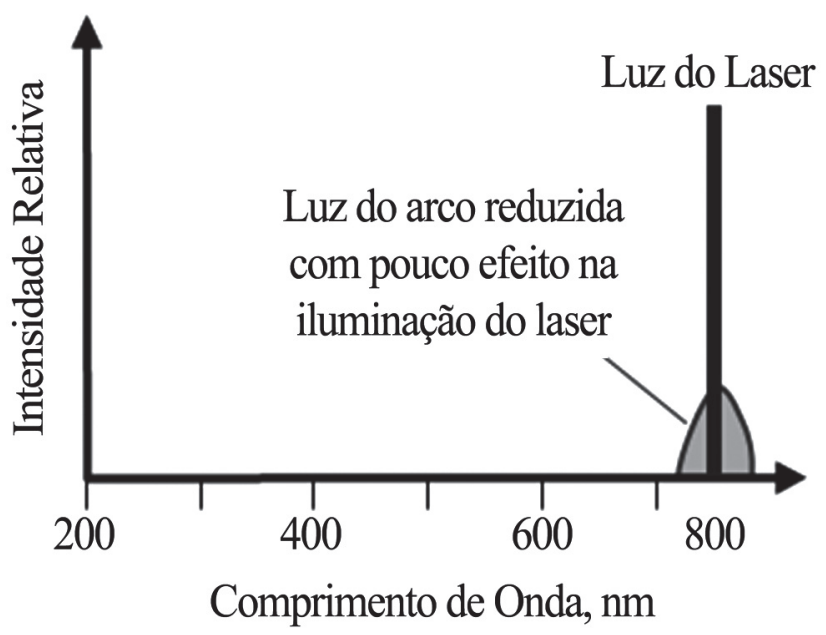

Com filtro de interferência

Figura 2. Princípio da Filtragem do Espectro [9]. 

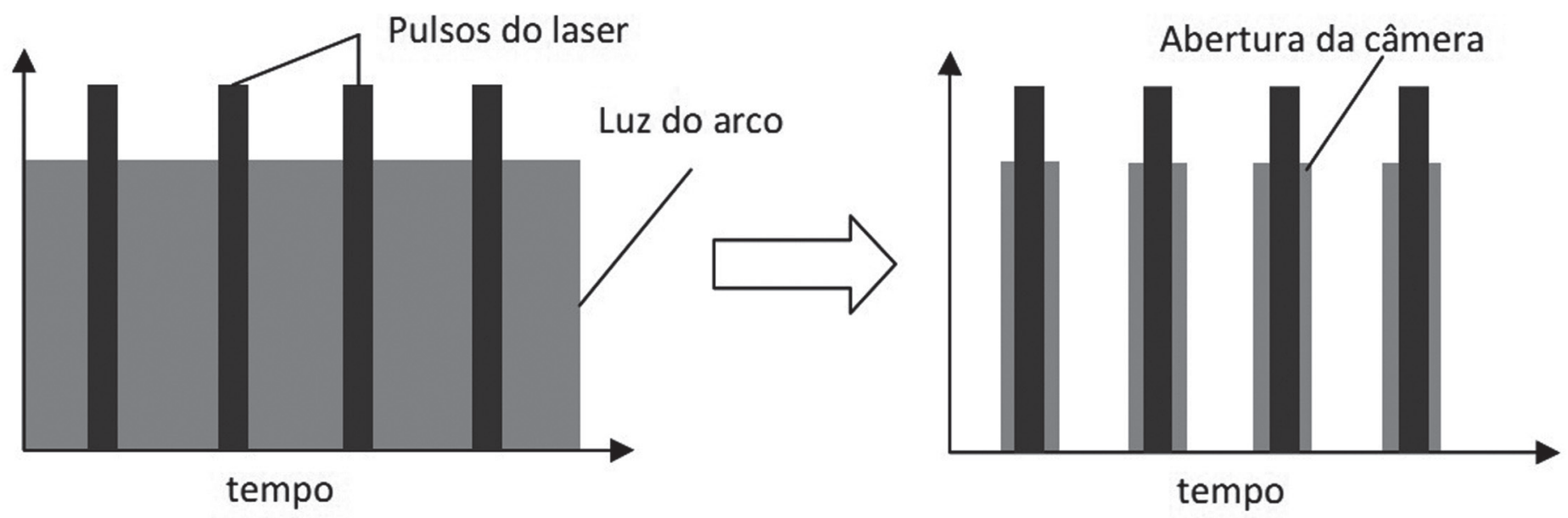

Figura 3. Ajuste do tempo de abertura da câmera para minimização da potência aplicada ao laser pulsado em comparação à natureza contínua da radiação do arco.
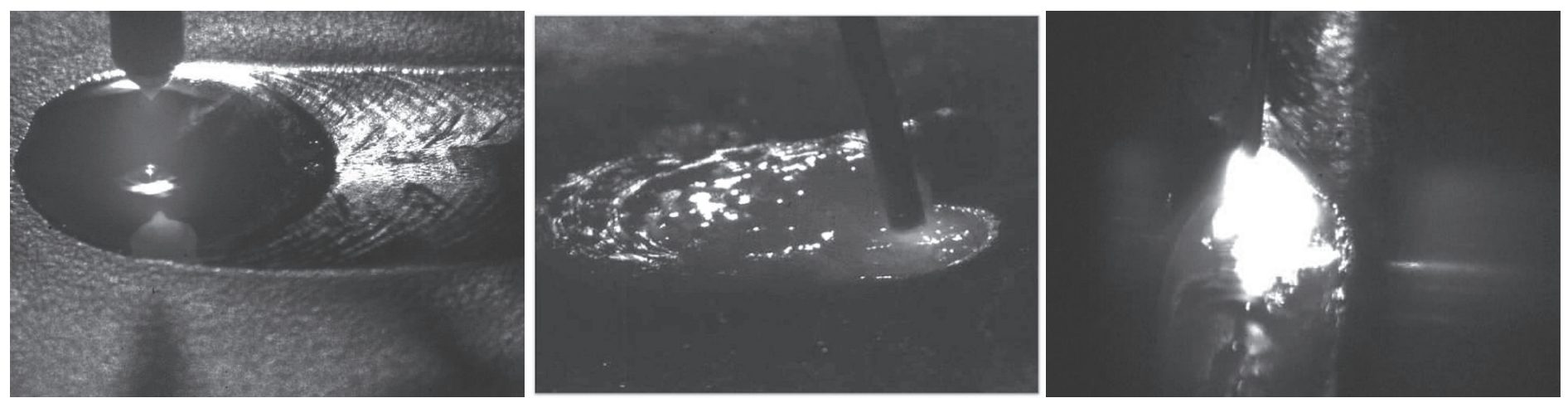

Figura 4. Sistema de visão com diodos laser de alta potência no infravermelho para TIG (esquerda) e MIG/MAG (centro e direita) [5, 13].

luminosidade do arco presente durante a aquisição de imagens. Esta técnica, apesar de eficiente, não é suficiente para "apagar" completamente o arco, Figura 1, e a luminosidade restante afeta a precisão e a nitidez com que se observa a poça fundida, não sendo suficiente em aplicações que demandem maior precisão.

Para que a radiação luminosa do arco não seja um problema durante a aquisição de imagens, utiliza-se a técnica de Filtragem de Espectro. O princípio da técnica é diminuir ou eliminar totalmente a luz do arco que alcança a câmera iluminando a área de solda com a luz de um laser [9]. A fim de minimizar os requerimentos de intensidade luminosa, o comprimento de onda da luz da fonte de iluminação deve ser selecionado onde a intensidade do arco é baixa. Um filtro passa-faixa estreito (filtro de interferência), no mesmo comprimento de onda da fonte de iluminação, é necessário para reduzir a luz do arco e apenas a luz do laser será capaz de afetar a câmera, como mostra a Figura 2.

O tempo de abertura da câmera também influencia na quantidade de luz adquirida durante a aquisição da imagem. Sendo assim, pode-se diminuir a intensidade luminosa do arco diminuindo o tempo de abertura (shutter) de cada quadro capturado [10]. Pulsando-se o laser dentro de cada tempo de abertura faz com que uma potência mínima seja necessária para que a luz do laser se sobreponha à radiação do arco, desde que o pulso do laser se situe dentro do tempo de abertura da câmera a cada quadro adquirido, como pode ser visto na Figura 3.

Três fontes de iluminação diferentes podem ser utilizadas para a iluminação da poça fundida: sistemas de laser, diodos LED (light emitting diode) e diodos laser [11, 12]. Os sistemas de laser, como, por exemplo, o laser de Nd-Yag, produz potência suficiente para iluminar a poça fundida, entretanto são sistemas caros e de menor flexibilidade. Os diodos LED são produtos de baixo custo e possuem uma grande gama disponível comercialmente, porém, não produzem potência luminosa suficiente para iluminar poça fundida. Já os diodos laser têm várias características que determinam sua utilidade como uma iluminação alternativa ao laser em si, com menor custo e possuindo potência suficiente quando se utilizado em conjunto. Trabalhos recentes $[5,13]$ mostram a aplicabilidade do uso de diodos laser de alta potência no infravermelho próximo para sistemas de visão em processo de soldagem, como pode ser observado na Figura 4.

Sendo assim, este trabalho tem por objetivo o desenvolvimento de um sistema de visão para processos de soldagem a arco, ou seja, um sistema capaz de visualizar a poça e arredores (junta e eletrodo) durante a soldagem sem interferência da radiação luminosa do arco elétrico, através da utilização de diodos laser de alta potência no infravermelho próximo como iluminação de auxílio, de baixo custo e flexível. Para tal, devem-se realizar 
atividades como: a caracterização dos espectros de emissão luminosa do arco do processo de soldagem, a criação de uma topologia de acionamento para o diodo de alta potência no infravermelho próximo e de seus circuitos de controle, respeitando suas limitações de uso e maximizando a potência luminosa emitida, a escolha dos equipamentos e componentes ópticos e, por fim o projeto e aplicação de um protótipo em processos de TIG (Tungsten Inert Gas) e MIG/MAG (Metal Inert Gas/Metal Active Gas).

\section{Métodos e Equipamentos}

O objetivo principal deste trabalho é o desenvolvimento de um sistema de visão para processos de soldagem através da utilização de diodos laser de alta potência no infravermelho próximo como iluminação de auxílio, de baixo custo e flexível.

A escolha do espectro em infravermelho próximo se dá principalmente por dois motivos. Sabe-se que a emissão do espectro de luz do arco em processos de soldagem abrange todo o espectro visível, além de emitir em níveis ultravioletas e infravermelhos. Porém, a emissão em infravermelho tem menor energia luminosa quando comparado ao espectro visível, facilitando a sobreposição do arco nesta região.

Por outro lado, para a obtenção de uma sequência de imagens iluminadas por um feixe de luz no infravermelho próximo é, de certa forma, mais simples e com custo muito baixo quando comparado aos níveis mais altos no infravermelho. Uma câmera CMOS (complementary metal-oxide-semiconductor) comum, geralmente, tem resposta no espectro do infravermelho próximo, o que não seria possível com o uso de iluminação no infravermelho. Um bom exemplo é visualização do LED infravermelho próximo de um controle remoto de TV por câmeras tão simples quando as de celulares. Câmeras infravermelhas são produtos específicos e, portanto, de alto custo, já câmeras comuns têm uma grande diversidade de modelos, a preços baixos, e alta flexibilidade.

Sabendo-se que a componente base para a fonte de iluminação deve ser um diodo laser, de alta potência e com emissão com espectro no infravermelho próximo e, existindo poucos semicondutores comercialmente disponíveis para a realização da triagem, escolheu-se o diodo laser pulsado disponível com maior potência encontrada, e maior aplicabilidade neste trabalho, de modelo SPL PL90_3, do fabricante OSRAM ${ }^{\circledR}$ como diodo laser de alta potência para o trabalho. A Tabela 1, abaixo, enumera as principais características deste diodo laser, segundo o banco de dados do fabricante.

Tabela 1. Características do diodo laser SPL PL90_3 [14].

\begin{tabular}{c|c|c}
\hline Parâmetros & Valor Típico & Unidade \\
\hline Ciclo de Trabalho & 0,1 & $\%$ \\
Comprimento de onda de emissão & 905 & $\mathrm{Nm}$ \\
Corrente Direta de Pico & 40 & $\mathrm{~A}$ \\
Divergência do Feixe (FWHM) & $11 \times 25$ & ${ }^{\circ}$ (grau) \\
Largura de espectro (FWHM) & 7 & $\mathrm{Nm}$ \\
Largura de Pulso & 100 & $\mathrm{Ns}$ \\
Potência de Pico de Saída & 75 & $\mathrm{~W}$ \\
\hline
\end{tabular}

Deve-se ressaltar, neste ponto, que o semicondutor escolhido é um diodo laser pulsado, ou seja, o componente suporta apenas determinados pulsos de corrente passando por sua junção em certo intervalo de tempo, não suportando a passagem contínua de corrente. Para este modelo especificamente, é importante observar que o diodo laser tem um ciclo de trabalho muito baixo, de $0,1 \%$, largura máxima de pulso de 100 ns e corrente de pico máxima de $40 \mathrm{~A}$.

Essas características, principalmente, devem ser levadas em consideração durante todo o desenvolvimento do sistema de visão, pois são estas os limites de funcionamento ótimo do diodo laser de alta potência e, portanto, os limites de projeto de todo o sistema de visão.

Os requisitos para a escolha de uma câmera para a realização da filmagem da região da junta iluminada pelo diodo laser escolhido são relativamente simples: esta deve responder ao espectro no infravermelho próximo da emissão do diodo laser (905 nm) e deve ter flexibilidade suficiente para a sincronização da obtenção das imagens com os pulsos de iluminação.

Escolheu-se uma câmera CMOS modelo PL-B776U, do fabricante PIXELINK, simplesmente por estar disponível em laboratório e não ser de alta velocidade (para se manter a meta de menor custo). Com resolução de 3.1 MP (2048 x 1536), comunicação USB 2.0, tempo de exposição programável de 100 $\mu$ s a 2 segundos e capacidade de resposta a trigger externo, esta câmera filma em até 48 quadros por segundo (fps) para menores resoluções [15]. Sua resposta ao espectro no infravermelho próximo é suficiente para a obtenção de imagens com qualidade.

Em uma análise inicial é possível observar que o tempo mínimo de exposição desta câmera (tempo no qual o shutter permanece aberto recebendo a imagem), de $100 \mu$ s, é muito superior à largura máxima de pulso do diodo laser de alta potência (100 ns). Como não houve recursos suficientes para a aquisição de uma câmera CMOS com menor tempo de abertura, espera-se que, ao suprir uma energia de pico muito alta a um conjunto de diodos laser durante um intervalo de tempo pequeno, a energia média da iluminação seja suficiente para sobrepor o arco contínuo no intervalo de tempo de exposição.

Tendo em vista todas as características dos componentesbase (diodo laser e câmera) tem-se a seguinte ordem para o desenvolvimento deste trabalho: desenvolvimento do projeto completo do Sistema de Visão, indo desde a criação, análise matemática e simulação computacional de uma topologia de acionamento dos diodos laser, até a escolha de todos os componentes eletrônicos e dos componentes integrantes de sistema óptico; e validação do sistema de visão através de testes de um protótipo deste em soldagens TIG e MIG/MAG.

\section{Projeto do Sistema de Visão}

\subsection{Topologia de Acionamento}

Os diodos laser de alta potência escolhidos para a criação do sistema de visão necessitam de um circuito capaz de fornecer pulsos de corrente com picos de até 40 A e ciclo de trabalho abaixo de $0,1 \%$ (Tabela 1 ). O chaveamento desta potência, portanto deve ser realizado de acordo com as características 


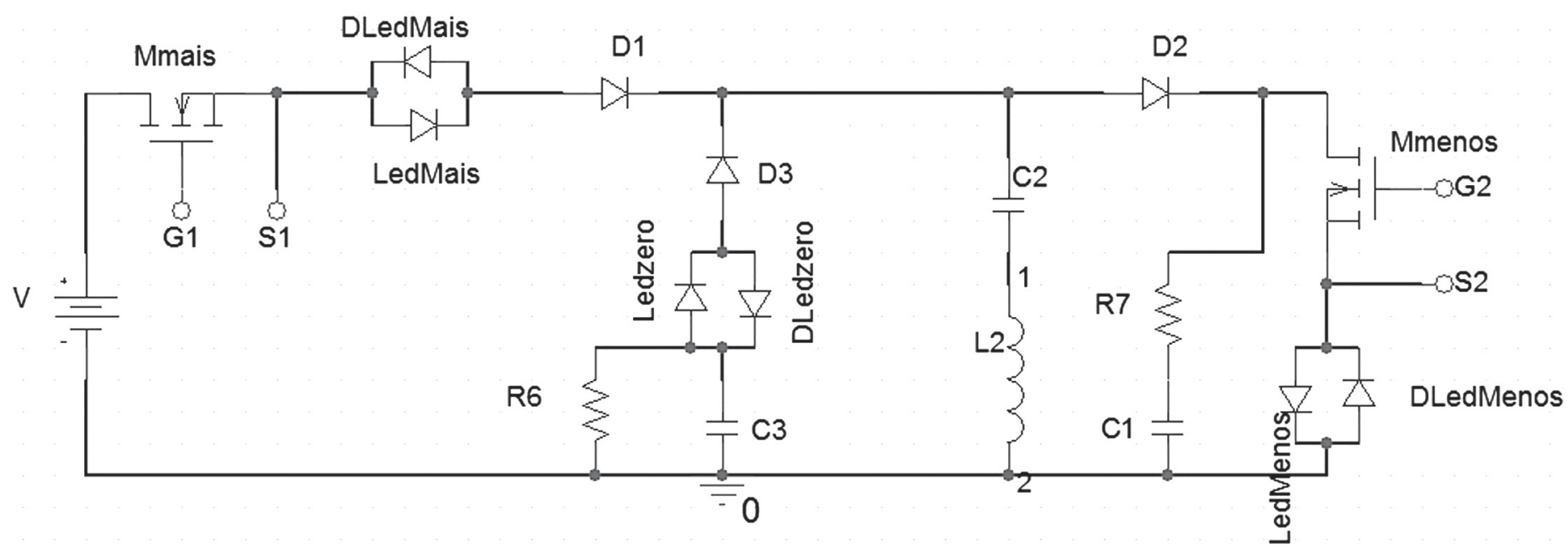

Figura 5. Topologia de acionamento dos diodos laser por circuito ressonante [16].
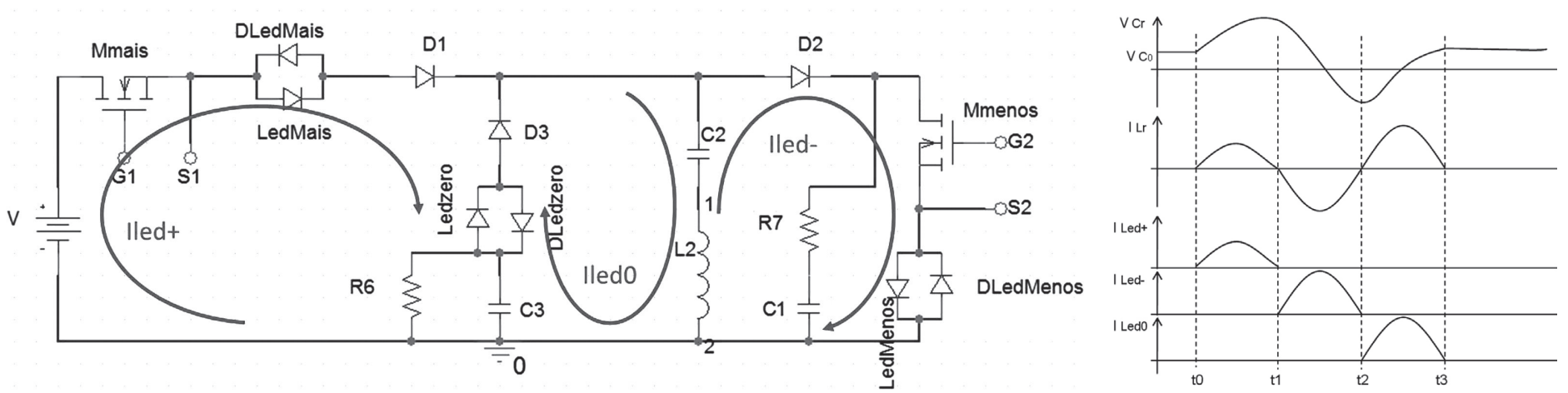

Figura 6. Esquema de funcionamento da topologia durante um ciclo de chaveamento [16].

deste semicondutor. A descrição resumida da topologia de acionamento vista a seguir pode ser aprofundada através de trabalhos anteriores $[10,16]$.

Através do uso da teoria de circuitos ressonantes e snubber, é possível construir uma topologia capaz de acionar os diodos laser com maior eficiência energética do que um circuito de chaveamento comum. A topologia do circuito de acionamento dos diodos laser é apresentada na Figura 5, onde os diodos laser são representados pelos componentes LedMais, LedMenos e LedZero.

Os componentes C2 e L2 formam o que se denomina de circuito ressonante LC série. Quando a ressonância ocorre, devido à aplicação da frequência apropriada de chaveamento, a energia armazenada em um elemento reativo é igual à fornecida pelo outro elemento reativo do sistema. Em outras palavras, a energia oscila entre um elemento e o outro durante a comutação das chaves presentes no circuito.

Os pares C1-R7 e C3-R6 formam o que é conhecido como circuito snubber e auxiliam a comutação das chaves. Os diodos D1, D2 e D3, colocados em série com os diodos laser e os diodos em antiparalelo DLedMais, DLedMenos e DLedZero têm a função de proteger os diodos laser contra uma tensão reversa acima do suportado por eles e o retorno de corrente durante o tempo onde não há chaveamento.
Através do chaveamento dos MOSFETs, Mmais e Mmenos, em uma determinada frequência e o ajuste dos valores dos componentes passivos do circuito, é possível aumentar a corrente sobre os diodos laser, maximizando sua emissão luminosa a cada tempo de abertura para a aquisição de uma imagem da câmera.

Em regime permanente, durante o semiciclo cuja primeira chave é fechada (Mmais), a fonte de tensão $\mathrm{V}$ alimenta $\mathrm{o}$ circuito ressonante, carregando o capacitor $\mathrm{C} 2$ e possibilitando a passagem de corrente pelo diodo laser (ou pelo conjunto de diodos) LedMais. Ao final do primeiro semiciclo, a chave Mmais é aberta e a segunda chave (Mmenos) é fechada. O capacitor $\mathrm{C} 2$, então completamente carregado, torna-se a fonte de tensão do circuito, possibilitando a passagem de corrente pelo diodo laser, ou conjunto de, LedMenos.

Ao final do segundo semiciclo, o capacitor C2 está inversamente polarizado. Quando a chave Mmenos é aberta, o capacitor $\mathrm{C} 2$ resultante torna-se a fonte de tensão, de polaridade oposta ao segundo semiciclo, e alimenta o circuito composto pelo último diodo laser, LedZero. A Figura 6 esquematiza o funcionamento da topologia durante um ciclo de chaveamento.

Para a obtenção da tensão de entrada V, utilizou-se a tensão da rede de 220 Vac retificada (onda completa), e calcularam-se todos os componentes da topologia para a obtenção de um pico máximo de corrente em $30 \mathrm{~A}$ e tempo de semiciclo de $800 \mathrm{~ns}$. 
Mesmo com o uso de 800 ns de duração do pulso ressonante, mantêm-se os valores médio e eficaz de trabalho abaixo do recomendado pelo fabricante, utilizando-se um ciclo de trabalho bem abaixo de $0,1 \%$ ( $800 \mathrm{~ns}$ em $25 \mathrm{~Hz}$ ).

Em uma condição extrema de sobrechaveamento, podem-se acionar os diodos laser de potência cerca de 18 vezes por quadro com o intervalo de $4 \mu$ s entre eles, a fim de aumentar o somatório de luz proveniente do sistema de visão para o excessivo tempo de abertura da câmera $(100 \mu \mathrm{s})$ e sem que haja prejuízo no funcionamento da topologia ressonante, Figura 7. Sendo assim, tem-se, efetivamente $28,8 \mu$ s de tempo somado de emissão dos diodos laser. Não há presença de diodos laser na terceira etapa (LedZero), pois este é o estágio com menor energia luminosa.

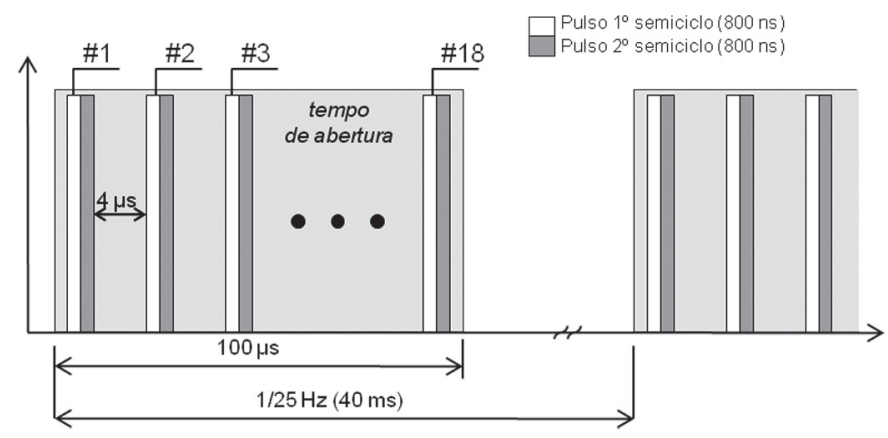

Figura 7. Esquema de sobrechaveamento dos diodos laser para compensação do tempo de abertura da câmera.

Toda a topologia ressonante foi equacionada analiticamente e seu comportamento foi determinado através de simulação computacional. Seu comportamento provou-se adequado para as limitações do uso de diodos laser e, através de testes experimentais do protótipo construído, as principais formas de onda adquiridas foram equivalentes ao encontrado nas simulações, finalizando o projeto da topologia de acionamento por circuitos ressonantes.

\subsection{Circuitos Auxiliares}

A topologia ressonante permite o uso do máximo de corrente em um intervalo de tempo pequeno, ideal para o acionamento dos diodos laser de alta potência. Isto só é possível através do chaveamento de semicondutores em alta frequência, ou seja, é necessário que as chaves semicondutoras recebam sinais de comutação nesta mesma frequência elevada.

Circuitos de controle de chaves semicondutoras podem ser implementados de diversas formas e com diferentes topologias, dependendo principalmente da frequência de trabalho, da própria chave semicondutora que se deseja controlar e do tipo de proteção necessária. Para altas frequências, e quando se é necessário o isolamento elétrico entre o circuito de controle e o circuito de potência, os circuitos auxiliares necessários para o comando de comutação de uma chave semicondutora é ilustrado na Figura 8.

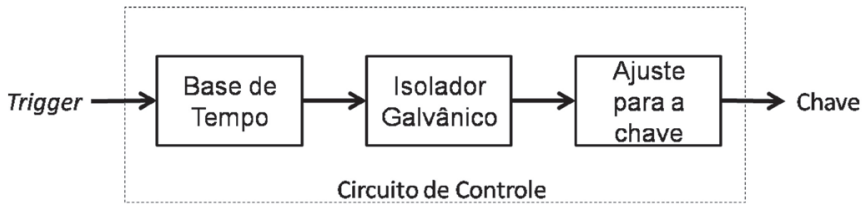

Figura 8. Circuito auxiliares para a comutação de uma chave semicondutora.

O sinal de trigger, externo ou interno ao sistema, é a entrada do circuito, geralmente indicando o momento onde a comutação da chave semicondutora deve ser realizado. Este sinal de trigger é, normalmente, um sinal de baixa frequência (entre $25 \mathrm{~Hz}$ e $1 \mathrm{kHz}$ ) e não respeita as limitações impostas pelo diodo laser. Sendo assim, um circuito é projetado para diminuir a duração do pulso de acionamento para a base de tempo desejada, com frequência elevada. Um circuito isolador protege o circuito de controle da alta potência no circuito que é controlado e, um último circuito, ajusta os valores de tensão e corrente para uma melhor comutação da chave semicondutora escolhida.

Para chaves onde o isolamento não é necessário, ou seja, onde as referências dos dois circuitos - controle e potência estão interligadas, pode-se apenas retirar o circuito intermediário (isolador), sem maiores alterações. Porém, para maior proteção do circuito gerador do trigger, manteve-se, neste trabalho, o isolamento galvânico para as duas chaves.

Os circuitos de trigger e base de tempo foram projetados, neste trabalho, com o uso de um microprocessador (MCU), menos sensível a ruídos externos. Através de um timer de 16 bits e um clock externo adequado, o MCU é capaz de "contar" tempos variados, sendo assim, possível a criação do trigger interno em baixa frequência $(25 \mathrm{a} 1000 \mathrm{~Hz})$ necessária para o acionamento das chaves comutadoras. $O$ tempo de instrução permite a criação dos pulsos da base de tempo, neste caso $800 \mathrm{~ns}$, para as duas chaves de forma consecutiva. O perfil programável do MCU permite, ainda, uma flexibilidade que não seria possível com um circuito analógico, como a utilização de interfaces com o usuário [10].

\subsection{Número de Diodos Laser}

Como último passo do roteiro de projeto da topologia ressonante de acionamento dos diodos laser, tem-se a escolha do número de diodos laser. Nesta etapa do projeto, deve-se levar em consideração fatores como a área que se deseja iluminar, a energia luminosa exigida e a corrente de pico sobre os diodos laser.

Portanto, a escolha do número de diodos laser em cada semiciclo da topologia ressonante é determinada pela corrente em circulação (que é em função, por sua vez, do número de diodos laser), pela área de iluminação desejada, pelo tamanho comercial dos componentes ópticos e, por fim, pelo orçamento disponível para a compra dos diodos laser.

Neste trabalho, especificamente, determinou-se o uso de oito diodos laser em série para a primeira etapa (LedMais) e onze diodos laser em série para a segunda etapa (LedMenos). Como o pico de corrente é maior sobre o segundo conjunto de diodos 
laser, optou-se por um maior número de diodos e, portanto, uma maior energia luminosa neste intervalo de tempo. O conjunto de dezenove diodos laser preenche uma área circular de cerca de $50 \mathrm{~mm}$ de diâmetro, ideal para os componentes ópticos comercialmente disponíveis e área suficiente para a iluminação da junta a ser soldada.

O esquema da distribuição dos diodos laser escolhido para este trabalho é mostrada na Figura 9. A distribuição homogênea e simétrica garante uma relação aproximadamente constante de energia luminosa por área iluminada, e sua forma circular sofre menores distorções que a maioria das formas geométricas quando projetada com algum ângulo em uma superfície plana.

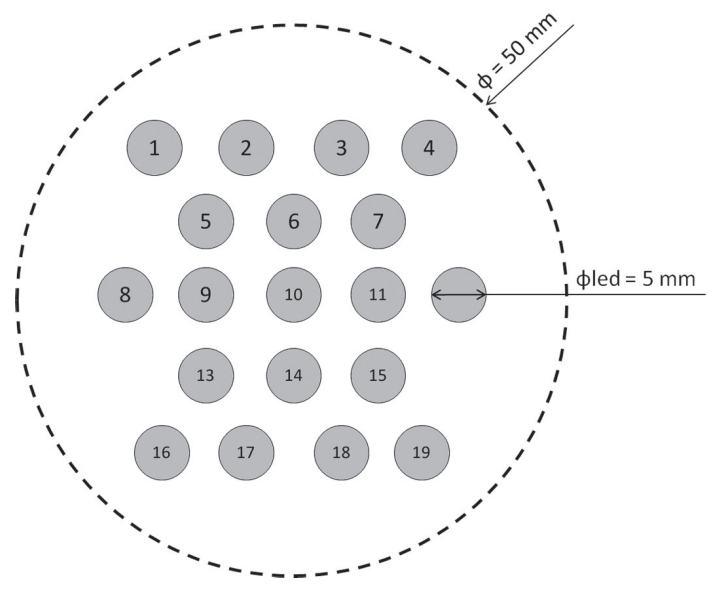

Figura 9. Esquema de distribuição dos diodos laser.

\subsection{Sistema Óptico}

Com uma técnica de acionamento dos diodos laser para a iluminação bem definida e estabelecida é muito importante, por fim, definir a forma com que a energia luminosa obtida pelo sistema será projetada na área de interesse de iluminação (região da junta a ser soldada), para que esta energia seja aproveitada sem a existência de grandes perdas.

Inicialmente, determinou-se que o sistema de visão deve estar afastado da região iluminada por, no mínimo, $250 \mathrm{~mm}$. Essa distância permite a segurança do equipamento contra, por exemplo, respingos durante o processo de soldagem ou o aquecimento pela proximidade da região do arco.

Portanto, tendo em vista um melhor aproveitamento da energia luminosa emitida pelos diodos laser sobre e, ainda, com o objetivo de uniformizar a distribuição da densidade luminosa na área de interesse, projetou-se um sistema óptico de projeção da luz no infravermelho próximo, como ilustra a Figura 10.

Os diodos laser são situados a uma distância de aproximadamente $140 \mathrm{~mm}$ de uma lente asférica (com distância focal de $39 \mathrm{~mm}$ ) e, pelo ângulo pequeno de divergência, considera-se um feixe paralelo. A lente asférica é responsável por condensar e projetar a luz, homogeneizando a distribuição da densidade luminosa sobre o seu foco. A lente convergente (com distância focal de $250 \mathrm{~mm}$ ) tem seu foco coincidente com o foco da lente asférica e, portanto, o feixe de luz é finalmente projetado de forma paralela para o plano de iluminação, situado a $250 \mathrm{~mm}$ do final do sistema óptico. O protótipo foi construído em alumínio, diminuindo a perda de energia luminosa ao longo do sistema óptico pela reflexão da luz em suas paredes.

\section{Validação do Sistema de Visão}

Para a verificação da compatibilidade da topologia ressonante proposta com as limitações dos diodos laser de alta potência, realizaram-se testes de durabilidade e eficiência do sistema de visão utilizando o diodo laser de alta potência.

Inicialmente, criou-se uma situação de sobrechaveamento dos diodos laser de potência a fim de verificar sua eficiência em uma situação de maior carga, ou seja, verificou-se a capacidade do sistema de visão em responder ao stress sem que haja queima de qualquer dos semicondutores ou perda significativa da vida útil desses. Após 16 horas de funcionamento do sistema, não houve degradação do semicondutor.

Como uma forma de estimar a vida útil do sistema de visão como um todo e, mais especificamente, a duração da vida útil dos diodos laser da alta potência, desenvolveu-se um teste de longa duração (burn in). Com a duração deste teste 77 horas

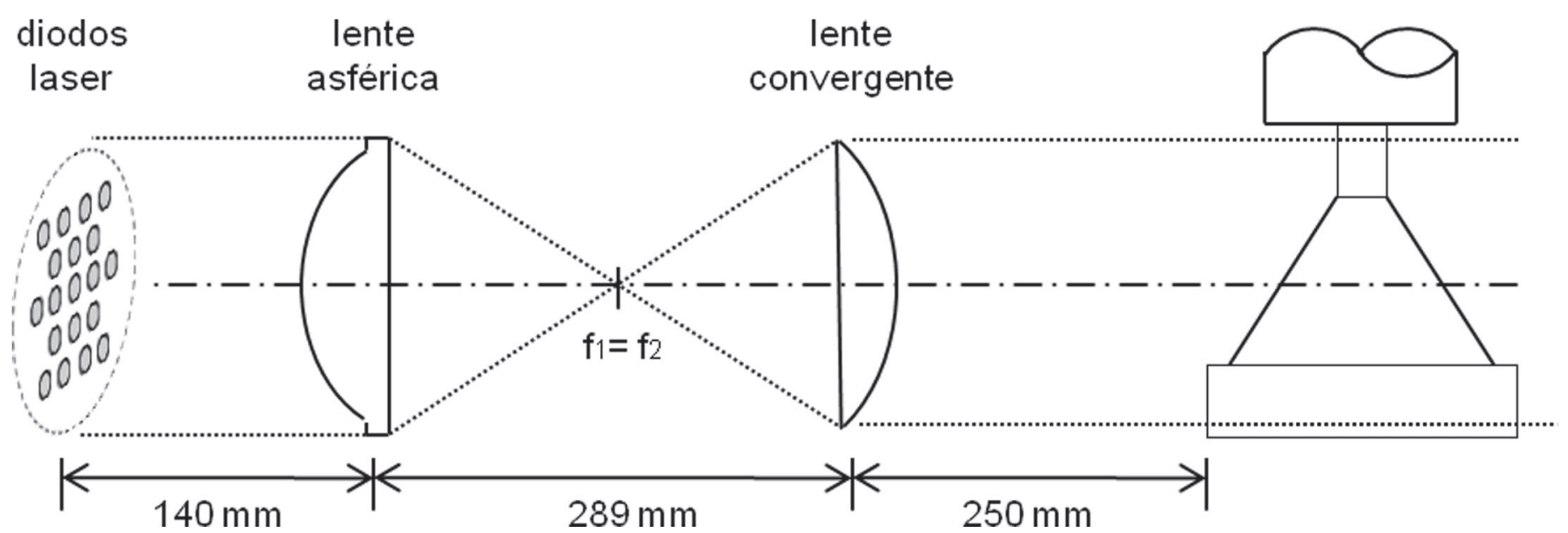

Figura 10. Sistema óptico de projeção da luz emitida pelos diodos laser. 
de acionamento ininterrupto, não foi possível estimar queda da eficiência da junção PN do diodo laser. Não houve, também, queima ou extinção da emissão luminosa em nenhum dos diodos laser testados, garantindo que o sistema de visão não degrada intencionalmente o semicondutor e, portanto, sua vida útil deve ser obtida através da previsão do próprio fabricante [10].

A seguir, pontos importantes a serem avaliados, de acordo com a metodologia adotada, são discutidos detalhadamente: a caracterização do espectro de emissão no infravermelho próximo (NIR) do sistema de visão em comparação à soldagem e a utilização do sistema de visão em soldagens TIG e MIG/ MAG.

\subsection{Caracterização dos Espectros no NIR}

Realizou-se um estudo da emissão e radiação infravermelha próxima em processos de soldagem a arco, em específico, em dois processos largamente utilizados, TIG e MIG/MAG, focando também sua influência por parâmetros como a corrente de soldagem e a proteção gasosa utilizada. Através do uso de um espectrômetro USB, aliado a um sistema de lentes para a focalização do arco e um algoritmo de aquisição do espectro, foi possível realizar um comparação quantitativa entre os processos e seus parâmetros. Neste item são enumerados os principais pontos deste estudo, que podem ser aprofundados através dos trabalhos [7,17].

Para ambos os processos, o aumento da intensidade de corrente resultou no aumento da emissão infravermelha. $\mathrm{O}$ aumento da tensão sobre um arco, de mesmo comprimento, aumenta a radiação de corpo negro no infravermelho e na emissão luminosa pelo retorno dos elétrons ao seu estado natural pelas partículas ionizadas. Para uma mesma intensidade de corrente, o processo MIG/MAG apresenta maior emissão e radiação infravermelha quando comparado ao processo TIG, devido à própria natureza física do arco.

$\mathrm{O}$ formato do espectro adquirido fornece informações importantes sobre o arco de soldagem. Seus picos indicam a composição da proteção gasosa utilizada e a temperatura atingida influencia na emissão de corpo negro. A soma dessas duas parcelas que caracteriza a emissão total do arco, como pode ser visto na Figura 11. Com base nos resultados obtidos

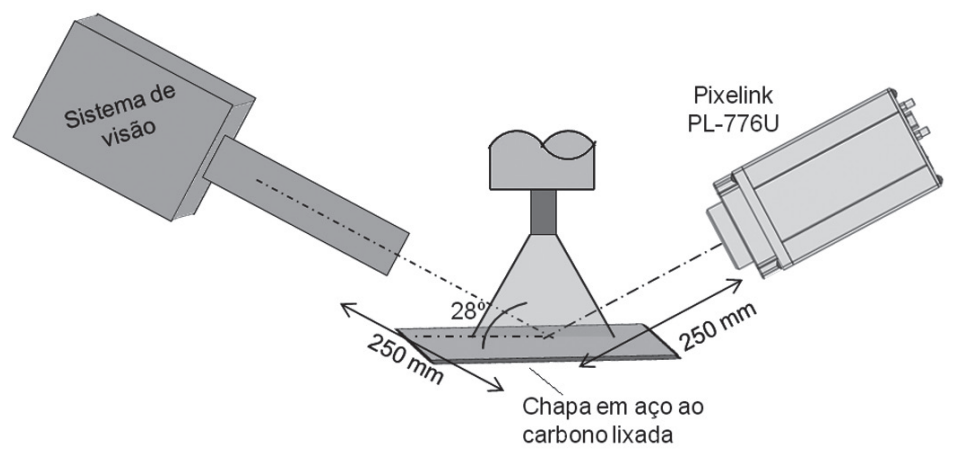

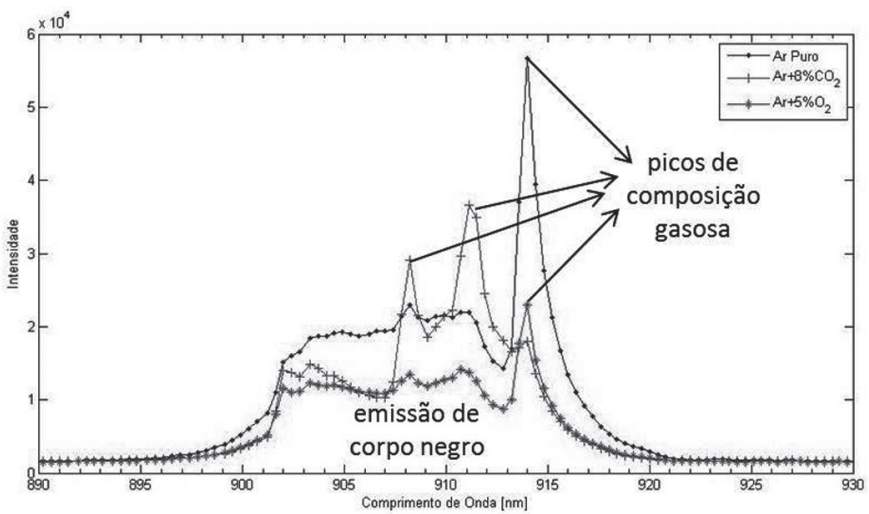

Figura 11. Ilustrativo de parcelas que compõem a emissão luminosa do arco de solda.

é possível se obter quantitativamente a intensidade luminosa necessária para sobreposição do arco durante a aquisição de imagens.

Através do comparativo entre os estudos de emissão de infravermelho próximo de processos de soldagem e do sistema de visão, utilizando-se do mesmo sistema de focalização e aquisição do espectro pelo uso de um espectrômetro USB, podese concluir que a luz que é emitida pelo sistema é suficientemente forte para sobrepor a luz do arco no processo TIG (cerca de 15 vezes maior) e do processo MIG/MAG (cerca de 3,5 vezes maior), para as condições de sobrechaveamento da topologia ressonante e tempo de abertura de $100 \mu$ s por quadro.

Por fim, um ponto muito importante observado durante a realização dos ensaios foi que as máscaras de solda com escurecimento automático mostraram-se sensíveis à radiação luminosa infravermelha do diodo laser. Ou seja, quando o sistema de visão é ligado, o operador utilizando a máscara de solda tem seu visor escurecido mesmo sem estar diretamente à frente do sistema de visão. Qualitativamente, pode-se concluir que a luz dos diodos laser é tão ou mais forte que a radiação luminosa do arco para que o fechamento automático da máscara de solda seja acionado. Esta observação também é importante para reforçar os cuidados com a visão do operador, cujos olhos podem sofrer danos (queimaduras), caso não se utilize EPI apropriado.

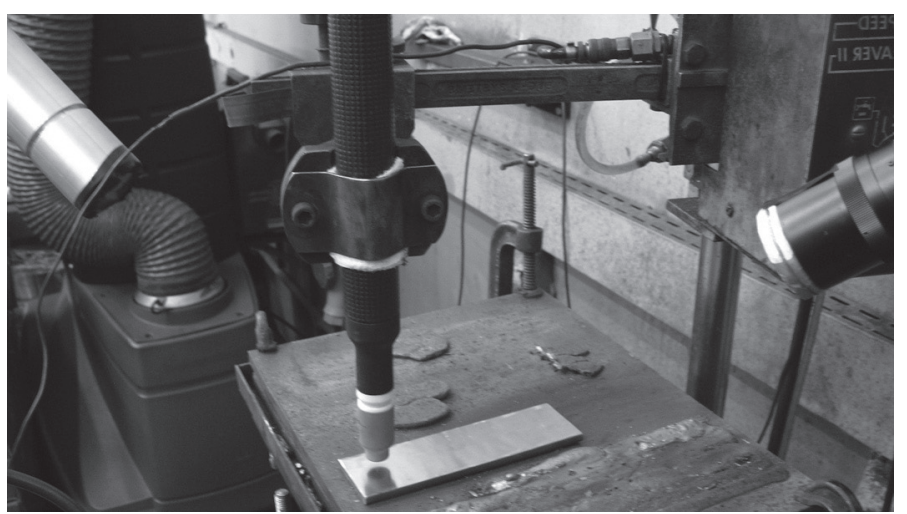

Figura 12. Esquemático (esquerda) e montagem real (direita) para a aquisição das imagens em soldagens TIG e MIG/MAG através do uso do sistema de visão. 
Tabela 2. Parâmetros medidos para a validação do sistema de visão em soldagem TIG e MIG/MAG.

\begin{tabular}{cccc}
\hline \multirow{2}{*}{ Parâmetro } & \multicolumn{3}{c}{ Valor Médio } \\
TIG & MIG/MAG & \multirow{2}{*}{ Unidade } \\
\hline Gás de Proteção & Ar puro & $\mathrm{CO}_{2}$ puro & - \\
Corrente & 107 & 100 & $\mathrm{~A}$ \\
Tensão & 12,9 & 17,5 & $\mathrm{~V}$ \\
Velocidade de Alimentação & - & 2 & $\mathrm{~m} / \mathrm{min}$ \\
Velocidade de Soldagem & 10 & 20 & $\mathrm{~cm} / \mathrm{min}$ \\
DBCP/DEP & 3 & 12 & $\mathrm{~mm}$ \\
\hline
\end{tabular}

Nota: DBCP é a distância entre o bico de contato e a peça em soldagens MIG/MAG e DEP é a distância entre o eletrodo e a peça em soldagens TIG.
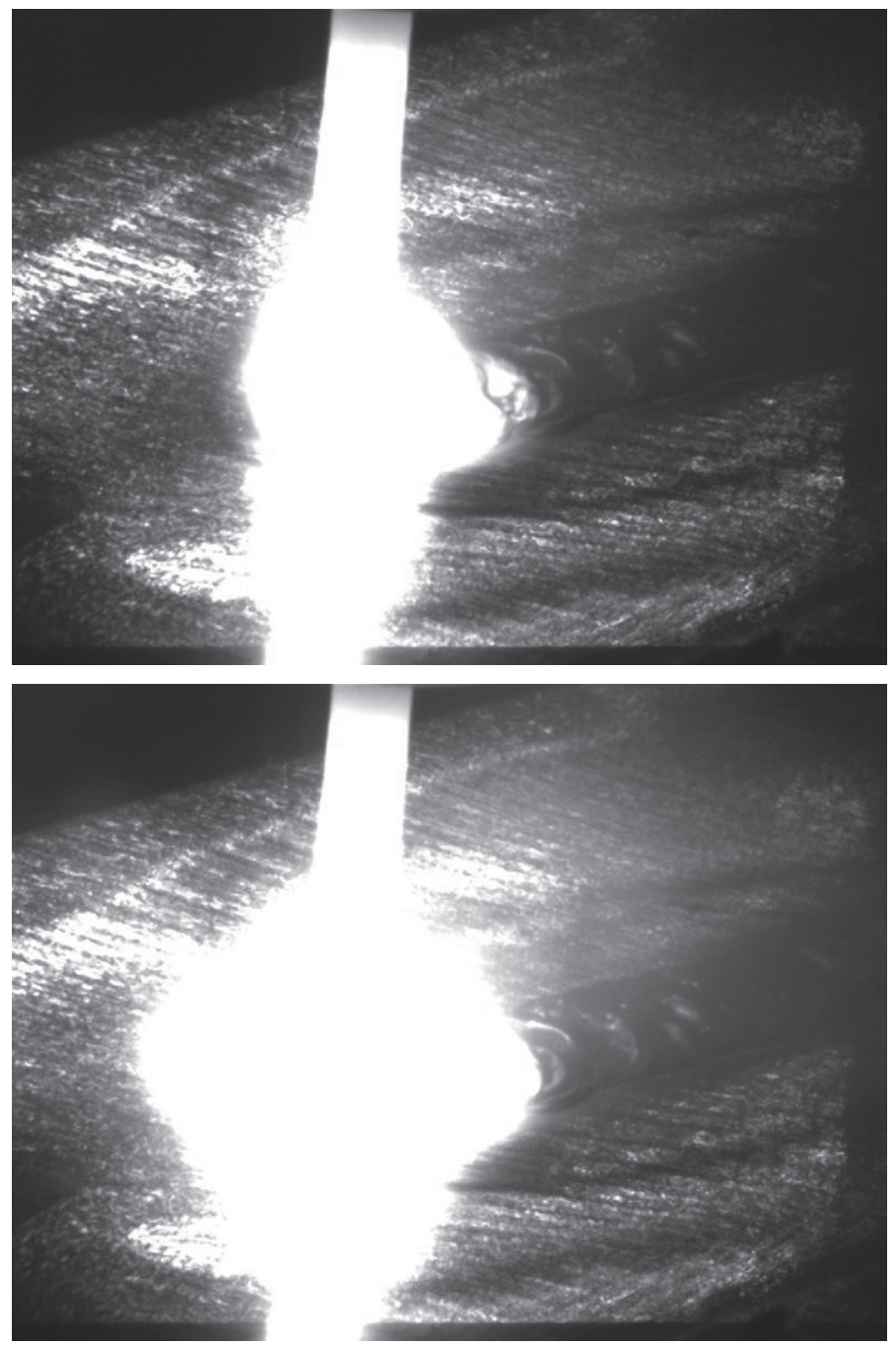
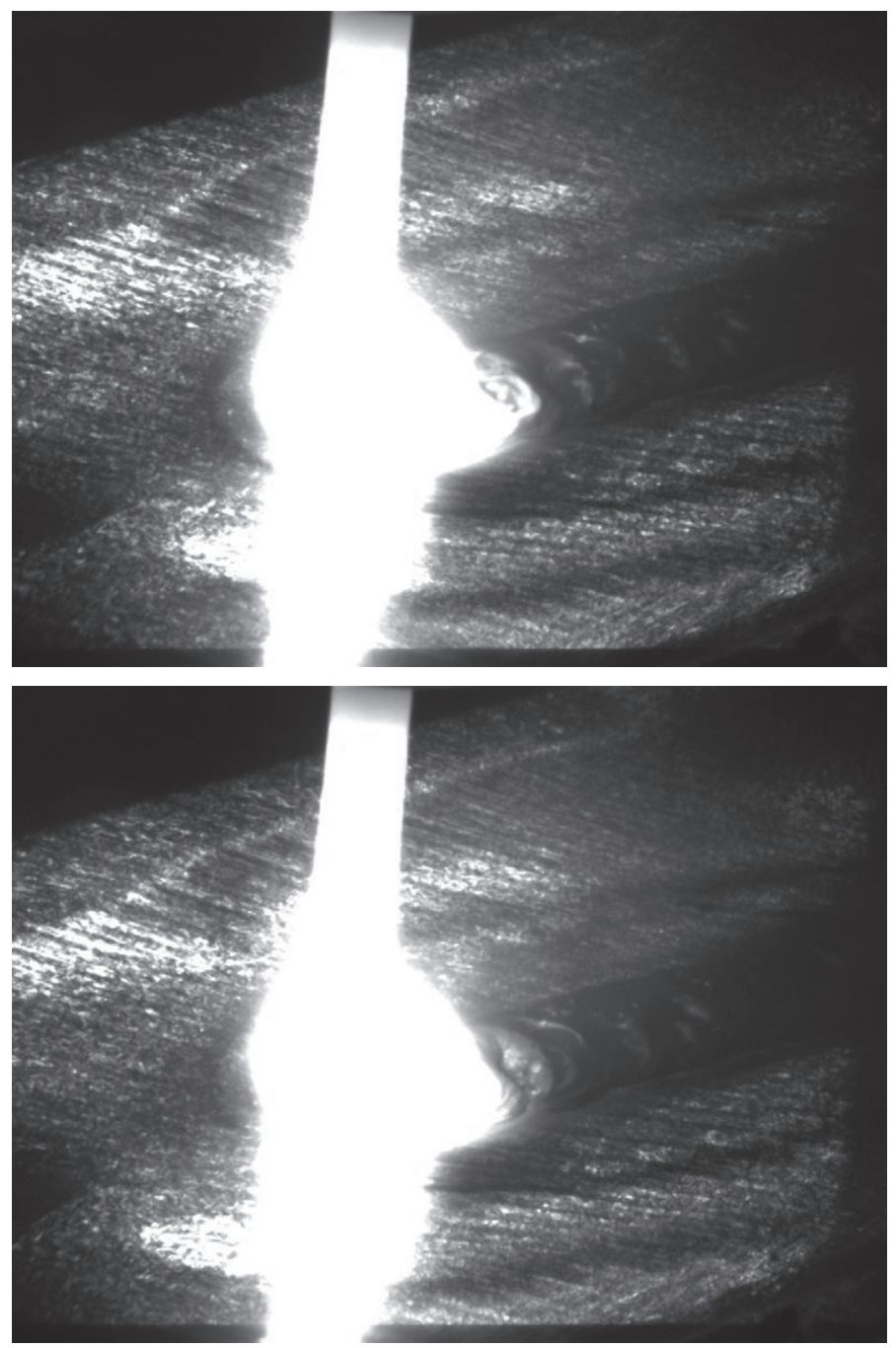

Figura 13. Imagens obtidas pelo sistema de visão em soldagem TIG (100 A, Ar puro - como escala adotar diâmetro do eletrodo igual a $2,4 \mathrm{~mm})$.

\subsection{Processos TIG e MIG/MAG}

Para a aquisição dos vídeos, ou da sequência de imagens do Sistema de Visão em soldagens in loco, a câmera foi configurada, através do programa fornecido pelo fabricante Pixelink Capture OEM, com um tempo de abertura de $100 \mu$ s, um total de 100 quadros (4 segundo de vídeo final com $25 \mathrm{fps}$ ) em formato
AVI com resolução de $800 \times 600$ pixels, controlado através de trigger externo. Utilizou-se um algoritmo em Matlab ${ }^{\circledR}$ para a decomposição do vídeo em uma sequência de imagens. A Figura 12 , a seguir, ilustra a montagem do sistema de visão e da câmera em relação à chapa de teste para a aquisição das imagens em todos os testes de soldagens (TIG e MIG/MAG).

Ambos os sistemas foram posicionados a uma mesma 

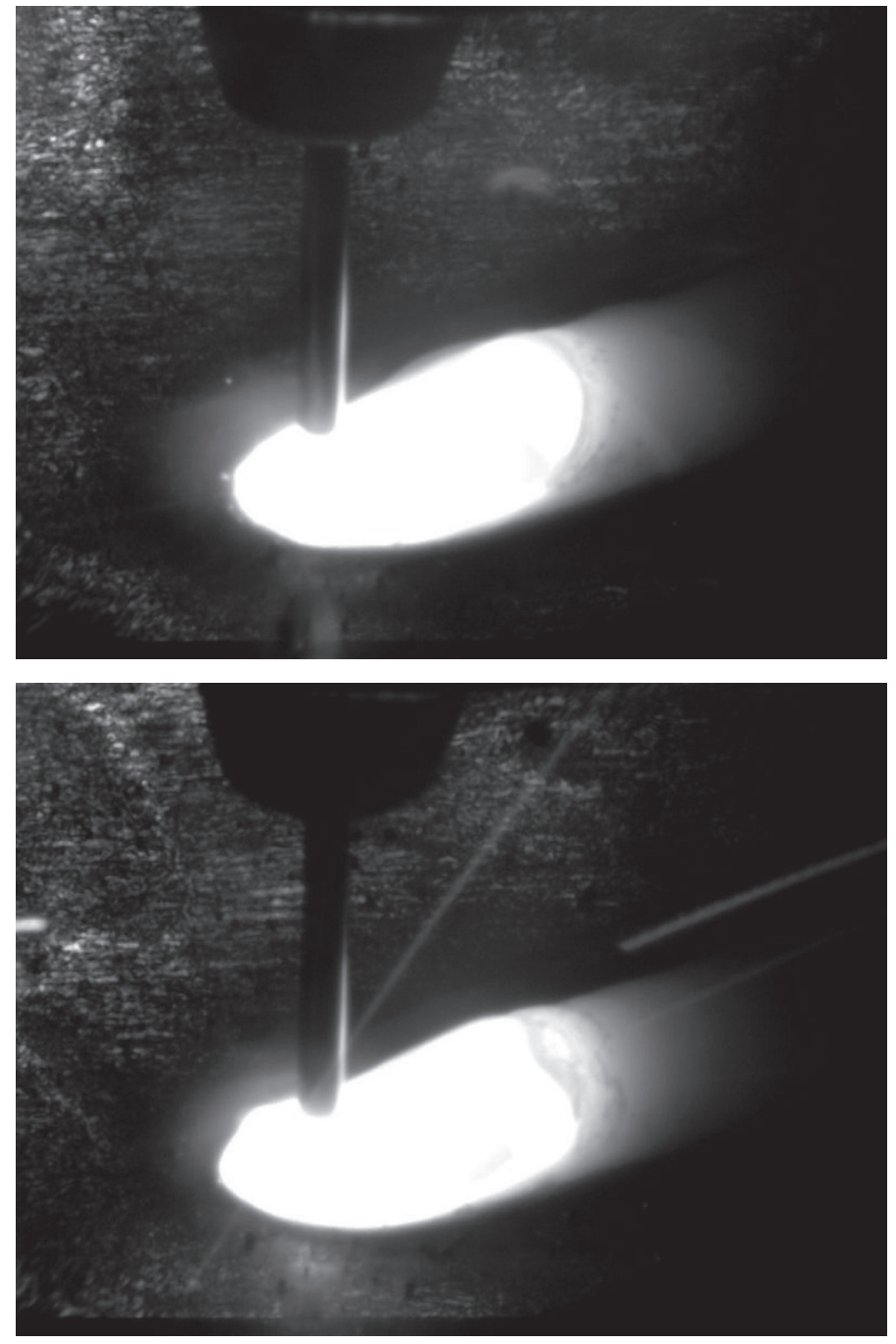
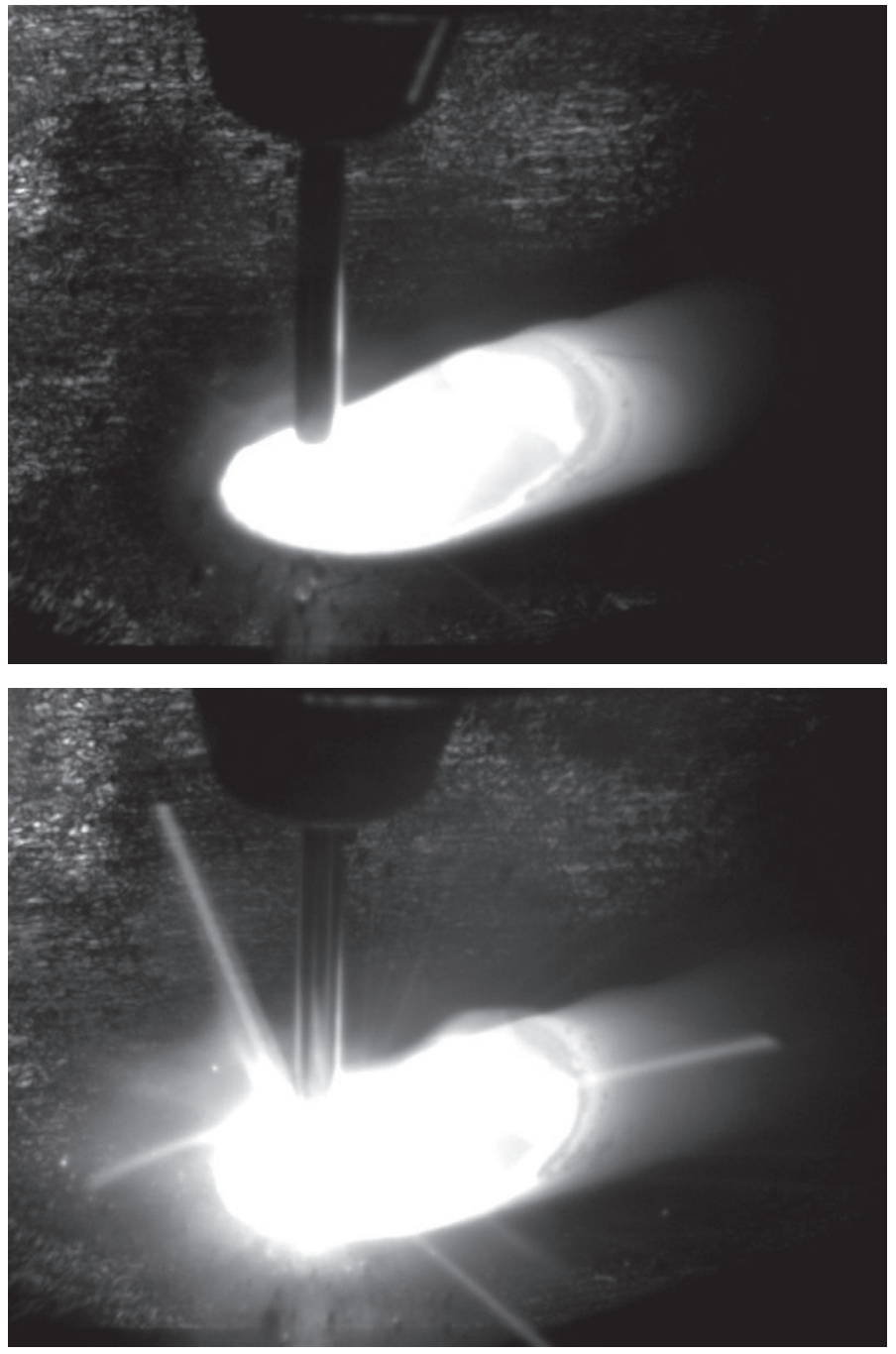

Figura 14. Imagens obtidas pelo sistema de visão em soldagem MAG (100 A, CO $\mathrm{CO}_{2}$ puro - como escala adotar diâmetro do arame igual a $1,2 \mathrm{~mm})$.

distância da área de interesse, sendo esta a distância mínima de segurança estabelecida anteriormente $(250 \mathrm{~mm})$. A iluminação é projetada na superfície da chapa com um ângulo de aproximadamente $28^{\circ}$, sendo a câmera posicionada para receber a reflexão máxima da luz do diodo laser, ou seja, com um ângulo simétrico em relação ao plano da chapa.

Para o teste do protótipo do sistema de visão em soldagens, procurou-se inicialmente um menor nível de corrente e, consequentemente, menor nível de emissão luminosa do arco. Os parâmetros selecionados para o processo de soldagem e a configuração do sistema de visão são listados na Tabela 2.

Exemplos dos quadros obtidos durante o uso do sistema de visão na soldagem TIG são mostrados na Figura 13. A título de estimativa de escala, deve-se considerar que o diâmetro do eletrodo de $2,4 \mathrm{~mm}$.

Observa-se, inicialmente, que a luz proveniente do sistema de visão não foi suficiente para sobrepor totalmente a luz do arco para o processo TIG com correntes em cerca de $100 \mathrm{~A}$. A superfície reflexiva da chapa lixada comportou-se como um refletor da luz infravermelha provinda do arco, saturando os pixels do CMOS da câmera durante toda a soldagem na região central inferior. Esse efeito causa uma perda de visibilidade na parte inferior da chapa, mas acredita-se que, mesmo que a luz do arco não fosse refletida diretamente para o obturador da câmera, a luz do sistema de visão não sobreporia a luz do arco na região central da imagem.

A título de comparação, trabalhos similares têm bons resultados obtidos com um sistema de visão baseado nos mesmos diodos laser de alta potência (Figura 4). Nestes trabalhos foi utilizada uma câmera com menor tempo de abertura (10 $\mu \mathrm{s})$ e se extrapolou os limites de utilização do diodo laser dados pelo fabricante com respeito ao ciclo de trabalho. Assim, estas opções destes autores auxiliaram na obtenção da sobreposição do arco em soldagens TIG para o sistema de visão utilizado nos referidos trabalhos.

Em contrapartida, pelos quadros ilustrados inicialmente (Figura 13), obtidos em diferentes instantes da aquisição, é possível observar que não há oscilação do perfil de iluminação da área da junta, indicando uma boa sincronização entre a emissão dos pulsos de NIR dos diodos laser e a abertura do 
shutter da câmera para a obtenção da imagem. De toda forma, como o sistema não foi capaz de sobrepor o arco para soldagem TIG com uma situação de menor emissão NIR (corrente baixa), conclui-se que não seria necessária a realização de novos testes com o aumento da emissão infravermelha ou em diferentes situações.

Exemplos dos quadros obtidos durante o uso do sistema de visão na soldagem MIG/MAG são mostrados na Figura 14. A título de estimativa de escala, deve-se considerar que o diâmetro do arame de $1,2 \mathrm{~mm}$.

Observa-se, inicialmente, que a luz proveniente do sistema de visão não foi suficiente para sobrepor totalmente a luz do arco para o processo MIG/MAG com correntes em cerca de $100 \mathrm{~A}$. Neste caso, utilizou-se um obturador mais fechado, permitindo menor entrada de luz quando comparado ao processo TIG. Não houve reflexão do arco sobre a chapa lixada, porém a poça fundida apresentou intensidades de pixels próximos à saturação do CMOS da câmera.

Observa-se que, assim como a topologia ressonante, o sistema de visão não foi capaz de sobrepor-se a luz infravermelha próxima vinda do arco em processo MIG/MAG, comportando-se de forma diferente ao processo TIG. O sistema óptico projetado neste trabalho promoveu uma melhor iluminação da região de interesse, resultando em imagens com melhor qualidade, melhor contraste e maior nível de detalhes. Quando se compara com sistemas de visão que utilizam apenas filtros de interferência (Figura 1), a melhoria nas imagens obtidas é notável, sendo possível observar os arredores da poça fundida e detalhes do processo que não são possíveis sem a ajuda de da iluminação dos diodos laser.

Assim como ocorrido nos testes em processos TIG, o sistema de visão mostrou-se com boa sincronização com o tempo de abertura para a aquisição dos quadros e sua iluminação provouse, também, homogeneizada ao longo da área de projeção da luz no plano da chapa. Este sistema, portanto, para essas condições de soldagem (tanto TIG quando MIG/MAG) e iluminação se encontra completamente apto para aplicações como seguidor de juntas.

Como o sistema não foi capaz de sobrepor o arco para soldagem MIG/MAG com uma situação de menor emissão NIR (corrente baixa e gás de proteção com menor emissão no espectro do filtro de interferência), conclui-se que não seria necessária a realização de novos testes com o aumento da emissão infravermelha ou em diferentes situações.

\section{Conclusões}

A topologia ressonante desenvolvida (simulada, equacionada e validada) para o acionamento dos diodos laser respeita as limitações de uso do componente, maximizando a potência luminosa emitida e, ainda, com alta eficiência energética e sem grandes demandas da rede elétrica. Os circuitos responsáveis pelo controle de chaveamento das chaves comutadoras foram projetados com a criação e controle do trigger através de um microcontrolador. O MCU é, ainda, responsável pelo envio de sinal de sincronia para a câmera, e seu algoritmo e sua natureza programável permite grande flexibilidade na aplicabilidade do sistema de visão em diferentes situações.

O sistema óptico projetado foi capaz de gerar uma iluminação homogênea em sua projeção na área de interesse. $\mathrm{O}$ uso de uma lente asférica em conjunto com uma lente convergente foi responsável pela condensação dos feixes provenientes das diferentes fontes pontuais.

Acredita-se que o uso de uma câmera CMOS com o tempo de abertura (exposure time ou shutter) muito superior ao tempo de acionamento máximo dos diodos laser é o principal responsável pela incapacidade do sistema de visão em sobrepor-se à luz provinda do arco. Mesmo com a utilização de sobrechaveamento, como ocorreu nos testes apresentados, a proporção de tempo de emissão contínua do arco desfavorece a influência dos picos de luz infravermelha provindos do diodo laser.

Observou-se que, ao longo do processo de soldagem, não há oscilação na iluminação gerada pelo acionamento dos diodos laser de alta potência, resultando em quadros com perfis de iluminação semelhante ao longo de todos os vídeos adquiridos. A homogeneização da iluminação ao longo dos quadros é um forte indicador que a sincronia temporal entre o acionamento dos diodos e a obtenção das imagens foi realizada de forma correta.

É possível se observar, também, que o sistema óptico foi capaz de homogeneizar a densidade de energia luminosa sobre a área de junta, sendo responsável pela capacidade de visualização de toda a região ao redor do arco, como o cordão de solda e, caso houvesse, a junta e seus arredores, tanto para as soldagens TIG quanto para soldagens MIG/MAG. Este sistema, portanto, para as condições de soldagem e iluminação apresentadas se encontra completamente apto para aplicações como seguidor de juntas.

\section{Referências Bibliográficas}

[1] BÁLSAMO, P.S.S., et al. Development of an experimental technique for studying metal transfer in welding: synchronized shadowgraphy. Int. J. for the Joining of Materials v., p. 2000.

[2] ZHANG, Y.M., R. KOVACEVIC, and L. LI. Adaptive Control of Full Penetration Gas Tungsten Arc Welding. IEEE Transactions On Control Systems Technology, v.4, n. 4, p. 1996. [3] ZHANG, Y.M., L. LI, and R. KOVACEVIC, Monitoring of Weld Pool Appearance for Penetration Control, in Trends in Welding Research, Proceedings of 4th International Conference. 1995: Gatinburg, Tennessee. p. 4.

[4] BASKORO, A.S., et al., Welding Penetration Control for Aluminum Pipe Welding Using Omnidirectional Visonbased Monitoring of Molten Pool, in 8th Internation Welding Symposium. 2008: Kyoto International Conference Center, Kyoto, Japan. p. 1.

[5] VILARINHO, L.O., et al., Dedicated Near-Infrared Vision System for Monitoring Welding Processes, in 20th International Congress of Mechanical Engineering. 2009: Gramado, RS, Brasil. p. 7.

[6] DUFFEY, T.P., S.E. SLOAN, and J. MAZUMDER, Measurement of Free Surface Deformation by Reflective Topography, in Trends in Welding Research, Proceedings of 4th International Conference. 1995: Gatinburg, Tennessee. p. 10. [7] MOTA, C.P., et al. Estudo da emissão de raios infravermelho 
próximo em processos de soldagem a arco. Soldagem e Inspeção, v.16, n. 1, p. 044-052, 2011.

[8] OGAWA, Y. and T. MORITA, Effect Of Shielding Gas And Wire Electrode On Mig Welding, in Proceedings of OMAE99, 18th International Conference On Offshore Mechanics and Arctic Engineering. 1999: St. Johns, Newfoundland, Canada. p. 13.

[9] HOUGHTON, M.A., et al. Vision Systems for Monitoring and Control of Arc Welding Operations. Soldagem e Inspeção, v.12, n. 4, p. 283-299, 2007.

[10] MOTA, C.P., Sistema de Visão por Infravermelho Próximo para Monitoramento de Processos de Soldagem a Arco, in PósGraduação em Engenharia Mecânica, Universidade Federal de Uberlândia. 2011: Uberlândia. p. 137.

[11] ABDULLAH, B.M., et al., Monitoring of TIG Welding using Laser and Diode Illumination Sources: a Comparison Study in International Conference on Eletronic Desing. 2008: Perang, Malasya. p. 4.

[12] ABDULLAH, B.M., et al., A Low Cost Vision System for Real-Time Monitoring os Welding Applications, in 14th International COnference on the Joining of Materials \& the 5th International Conference on Education in Welding. 2007: Helsingor, Denmark. p. 13.

[13] VILARINHO, L.O., et al., Sistema de Visão por infravermelho p'roximo Dedicado ao Monitoramento de Processo de Soldagem, in VI Congresso Nacional de Engenahria Mecânica (CONEM). 2010: Gramado, RS, Brasil. p. 8.

[14] Nanostack Pulsed Laser Diode in Plastic Package 75 W Peak Power. 2006, OSRAM OPTO SEMICONDUCTORS: Regensburg.

[15] PL-B776F Firewire, PL-B776G Gigabit Ethernet, PLB776U USB 2.0, PIXELINK: Ontario.

[16] MOTA, C.P., et al., Topologia De Acionamento De Diodos Laser De Alta Potência Visando Sua Utilização Em Auxílio Visual A Processos De Soldagem, in VI Congresso Nacional de Engenharia Mecânica (CONEM). 2010: Campina Grande, Paraíba. p. 10.

[17] MOTA, C.P., et al., Study Of The Efficiency Of A Vision System For Monitoring And Development Of Arc-Welding Process, in 21st Brazilian Congress of Mechanical Engineering (COBEM). 2011: Natal, RN. p. 10. 